\title{
Interaksi Tingkah Laku Ikan Cupang Jantan dan Betina (Betta splendes) Pada Masa Kawin
}

\author{
${ }^{1}$ Anwari Adi Nugroho, ${ }^{2}$ Ulin Nuha Latifa, ${ }^{3}$ Nova Yanti Rahayu, ${ }^{4}$ Arif Fajar Setyawan \\ 1,2,3,4 Prodi Pendidikan Biologi, Universitas Veteran Bangun Nusantara Sukoharjo \\ Email Korespondensi:bio_anwary@yahoo.com
}

Article Info
Article History
Received: 05 February
2020
Revised: 03 March 2020
Published: 25 March 2020
Keywords
Betta Fish, Interaction,
Behavior


Informasi Artikel
Sejarah Artikel
Diterima: 05 Februari 2020
Direvisi: 03 Maret 2020
Dipublikasi: 25 Maret 2020
Kata kunci
Ikan Cupang, Interaksi,
Tingkah Laku

\begin{abstract}
Betta splendes are commonly known as betta fish. During mating, male and female betta fish have a unique behavior, when separated or combined. This study aims to determine the interaction patterns of male and female betta fish behavior during mating. This research is a descriptive exploratory research using ad libitum sampling research method. The tools used in the form of insulated glass aquariums and fishing nets, the material needed is 6 betta fish. Data was taken using observation sheets, observation notes, and documentation tools. Data analysis using descriptive analysis techniques that describe the behavior that appears during the observation. The results of observations in different containers showed that the behavior of the male betta fish was the most dominant is making bubbles while the behavior of the female betta fish was the most dominant silence at the bottom of the aquarium. In one container the results of the behavior of the betta fish were the most dominant was swimming around the aquarium while the behavior of the female betta fish the most dominant is staying at the bottom of the aquarium.

Abstrak

Betta splendes dikenal secara umum dengan sebutan ikan cupang. Pada masa kawin, ikan cupang jantan dan betina memiliki tingkah laku yang khas, pada saat terpisah maupun digabungkan. Penelitian ini bertujuan untuk mengetahui pola interaksi tingkah laku ikan cupang jantan dan betina pada masa kawin. Penelitian ini merupakan penelitian deskriptif eksploratif dengan metode penelitian ad libitum sampling. Alat yang digunakan berupa aquarium kaca bersekat dan jaring penangkap ikan, bahan yang dibutuhkan adalah ikan cupang sebanyak 6 ekor. Data diambil menggunakan lembar observasi, catatan pengamatan, dan alat dokumentasi. Analisis data menggunakan teknik analisis deskriptif yaitu mendeskripsikan perilaku yang muncul selama pengamatan. Hasil pengamatan dalam wadah berbeda didapatkan hasil bahwa perilaku ikan cupang jantan paling dominan adalah membuat gelembung sedangkan perilaku ikan cupang betina yang paling dominan adalah diam didasar aquarium. Dalam satu wadah didapatkan hasil perilaku ikan cupang jantan paling dominan adalah berenang memutari akuarium sedangkan perilaku ikan cupang betina yang paling dominan adalah diam di dasar aquarium.
\end{abstract}

Sitasi: Nugroho, A.A., Latifa, U.N., Rahayu, N.Y., \& Setyawan, A.F. (2020). Interaksi Tingkah Laku Ikan Cupang Jantan dan Betina (Betta splendes) Pada Masa Kawin. Science Education and Application Journal (SEAJ). 2 (1), 27-34.

\section{PENDAHULUAN}

Ikan cupang (Betta splendes) yang dikenal dengan sebutan fighting fish adalah salah satu jenis ikan air tawar yang populer dikalangan pecinta ikan hias. Postur tubuh ikan cupang memanjang dan pipih (compresed) apabila dilihat dari anterior atau posterior (Yustina 2003). Sedangkan ukuran tubuh ikan cupang relatif kecil dengan panjang tubuh kurang lebih 3,5 cm untuk indukan betina dan $4 \mathrm{~cm}$ untuk indukan jantan untuk umur sekitar 3-4 bulan (Streba, 1983; Lee, 1989). Ikan cupang dapat dibedakan berdasarkan tampilan fisik yang dimiliki. Karakteristik 
ikan cupang jantan yaitu warna tubuh yang cerah, tubuh berbentuk ramping, sirip ekor dan sirip anal panjang. Ikan cupang jantan memiliki pertumbuhan yang lebih cepat dibandingkan dengan cupang betina (Satyani, 2017). Sementara ikan cupang betina memiliki karakteristik warna tubu kurang menarik, perut berbentuk gemuk, ukuran sirip ekor dan sirip anal yang pendek.

Menurut Susanto (1992) habitat ikan cupang berada di air tawar seperti sungai, sungai, rawa atau selokan. Kemampuan adaptasi ikan cupang tergolong sangat baik, cupang mampu beradaptasi pada tempat yang tidak terlalu luas dan tidak memungkinkan untuk melakukan perkembangbiakan. Menurut Axelrod \& Schultz (1983) cupang suka pada tempat yang ditumbuhi banyak tumbuhan air. Hal tersebut bermafaat bagi cupang untuk perlindungan diri dari pemangsa khususnya dari burung - burung pemangsa ikan.

Reproduksi pada ikan cupang dikenal dengan istilah pemijahan, pemijahan ikan cupang tidak membutuhkan wadah yang luas, cukup menggunakan akuarium ukuran kecil, ember maupun baskom, dapat juga menggunakan wadah atau toples (Lingga \& Susanto, 2003). Pada masa pemijahan, cupang memiliki tingkah laku yang khas terutama interaksi antara ikan cupang jantan dengan betina. Cupang memijah pada sore hingga malam hari, pada kondisi lingkungan yaitu pada suhu sekitar $26,5^{\circ}-31,0^{\circ} \mathrm{C}$ dan $\mathrm{pH}$ 6,0-8,0 (Dewantoro, 2001; Lingga $\&$ Susanto, 2003). Sebelum melakukan proses reproduksi, ikan cupang jantan dan ikan cupang betina akan saling berinteraksi dengan saling tatap. Selanjutnya ikan cupang jantan akan mengejar ikan cupang betina dengan cara memperlihatkan sirip ekor untuk menarik perhatian sang betina. Setelah ikan cupang betina tertarik maka ikan cupang jantan akan melipatkan badannya pada tubuh betina, dan saat melipatkan diri, cupang betina melepaskan telur dan jantan mengeluarkan spermanya (Axelrod, 1995).

Telur ikan yang sudah dibuahi akan turun dan ditangkap oleh ikan cupang jantan, selanjutnya telur tersebut akan disimpan didalam sarang busa yang telah dibuat oleh ikan cupang jantan. Telur akan menetas pada kurun waktu sekitar 3 hari. Sedangkan ikan cupang betina akan diusir oleh cupang jantan untuk menjauhi telur-telurnya (Atmajaja, 2008). Penelitian terhadap larva/ benih ikan cupang (Satyani, 2017; Yusuf et.al., 2015) telah banyak dilakukan namun terkait pola interaksi ikan cupang dalam masa kawin sangat minim. Interaksi tingkah laku ikan cupang jantan dengan betina pada masa kawin perlu diketahui/ diteliti lebih lanjut. Pola tingkah laku tersebut dapat menjadi acuan bahwa ikan cupang pada masa kawin memiliki tanda-tanda tingkah laku khas. Berdasarkan uraian latar belakang maka perlu dilakukan penelitian tentang pola interaksi perilaku ikan cupang jantan dan betina pada masa kawin.

\section{METODE}

1. Tempat, Waktu dan Metode Penelitian

Penelitian dilaksanakan di laboratorium biologi Universitas Veteran Bangun Nusantara Sukoharjo dan dilaksanakan pada bulan Desember 2019- Januari 2020. Penelitian ini merupakan jenis penelitian deskriptif eksploratif yang dilakukan dengan cara mengamati perilaku ikan cupang jantan dan betina secara langsung berdasarkan pola perilaku yang terjadi. Metode yang digunakan adalah metode ad libitum sampling yaitu penelitian dengan cara mengamati seluruh aktivitas yang terlihat dengan menggunakan batasan aktifitas berdasarkan fakta lapangan (Altmann, 1974). Aktivitas yang diamati secara khusus aktivitas ikan cupang pada masa kawin.

2. Alat dan Bahan

Alat yang digunakan dalam penelitian antara lain aquarium kaca bersekat sebanyak 3 buah dengan ukuran sama dan jaring penangkap ikan sebanyak 1 buah. Bahan yang digunakan adalah ikan cupang jantan sebanyak 3 ekor dan cupang betina sebanyak 3 ekor. 


\section{Kualifikasi Ikan Cupang}

Ikan cupang yang digunakan dalam penelitian ini berupa ikan cupang jantan dan betina dari jenis ikan cupang halfmoon (Betta splendes). Umur ikan cupang jantan dan betina sekitar 5 bulan dengan ukuran ikan cupang jantan rata-rata $3,2 \mathrm{~cm}$ dan betina ratarata $3 \mathrm{~cm}$.

4. Prosedur Kerja

Prosedur penelitian pola perilaku ikan cupang jantan dan betina pada masa kawin. Dapat dilihat pada gambar 1 .

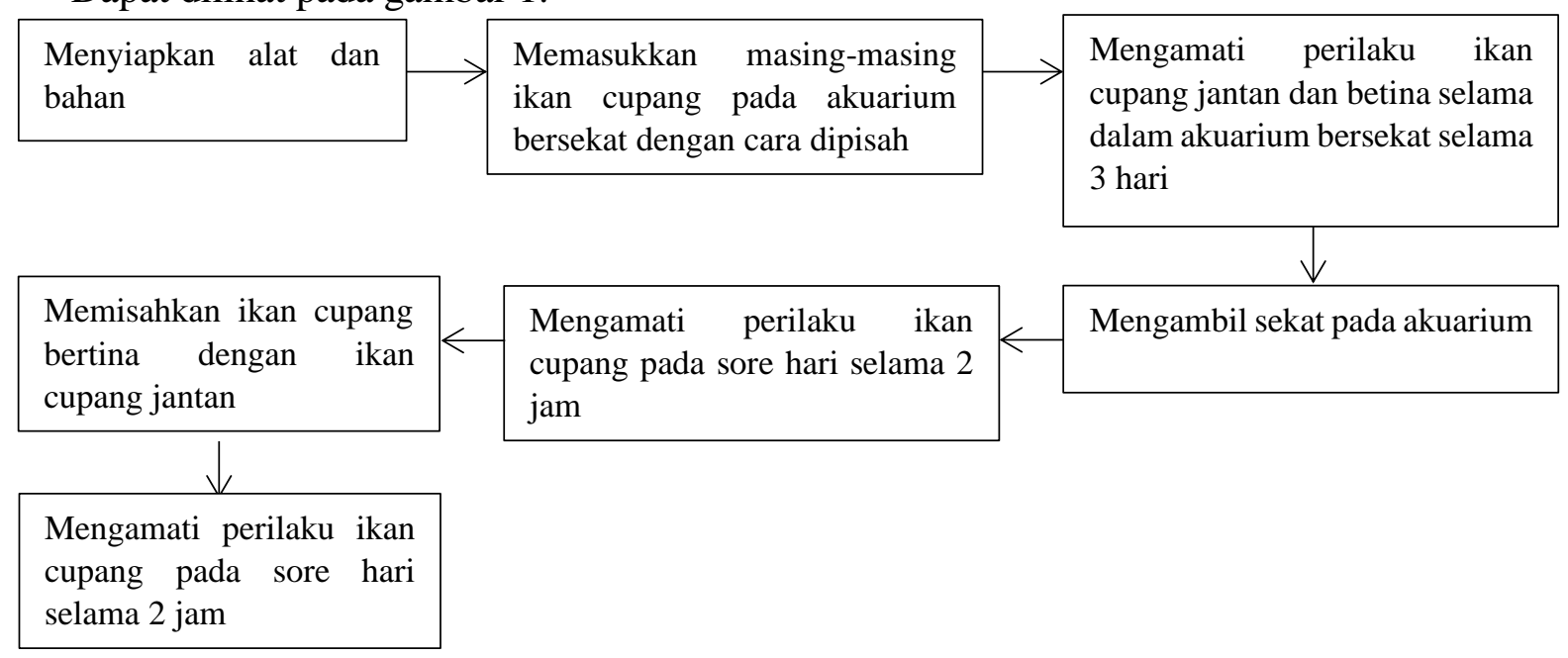

\section{Gambar 1. Skema Prosedur Penelitian}

Penjelasan Gambar 1 sebagai berikut: 1) Menyiapkan alat dan bahan dalam penelitian, 2) Memasukkan ikan cupang ke dalam aquarium bersekat dengan cara dipisah. 3) Mengamati perilaku ikan cupang jantan dan betina selama 3 hari pada waktu pagi dan sore hari selama 1 jam, 4) Mengambil sekat pada aquarium sehingga ikan cupang jantan dan betina bersatu dalam satu wadah, 5) Mengamati kembali perilaku ikan cupang jantan dan betina selama 2 jam pada waktu sore hari. Desain penelitian yang telah dilaksanakan dapat dilihat pada Gambar 2.
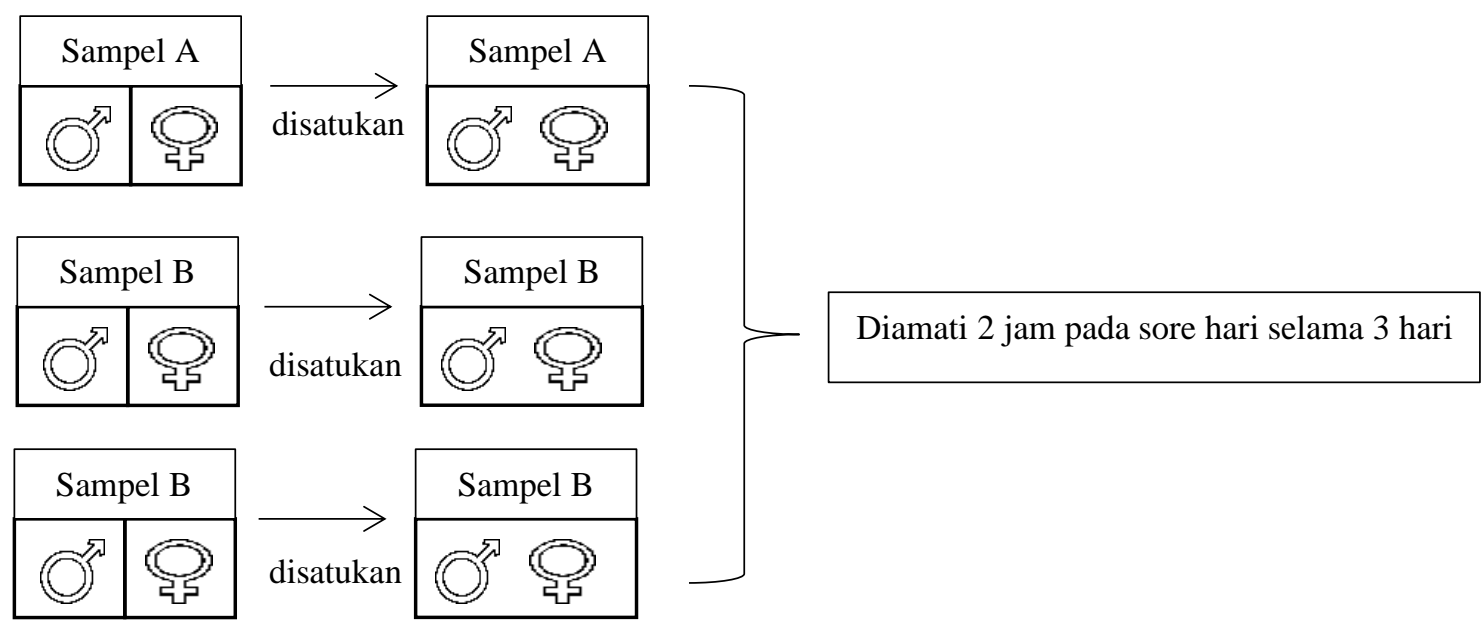

Gambar 2. Desain Penelitian

5. 


\section{Pengambilan Data}

Data diambil dengan cara pengamatan menggunakan lembar observasi, catatan pengamatan, dan alat dokumentasi. Data yang sudah dikumpulkan dianalisis menggunakan Teknik analisis deskriptif yaitu mendeskripsikan perilaku-perilaku ikan cupang jantan dan betina yang muncul selama pengamatan.

\section{HASIL DAN PEMBAHASAN}

Betta splendes dikenal secara umum dengan sebutan ikan cupang, merupakan jenis ikan hias yang banyak diminati. Jenis ikan ini memiliki daya tarik khusus yaitu pada bagian sirip tubuhnya hingga ekornya yang memiliki warna mencolok dan indah. Pada masa kawin, ikan cupang jantan dan betina memiliki tingkah laku yang khas, pada saat terpisah maupun digabungkan. Pada penelitian ini dilakukan tentang interaksi ikan cupang jantan dan ikan cupang betina pada masa kawin dengan cara menempatkan ikan cupang pada wadah yang berbeda selama 3 hari dan diamati selama 1 jam kemudian menggabungkannya dalam satu wadah dan diamati selama 2 jam.

Interaksi Tingkah Laku Ikan Cupang Dalam Wadah Berbeda. Selama 3 hari dilakukan pengamatan 3 sampel (sampel A, B, dan C) dengan masing-masing sampel berisi ikan jantan dan betina dalam wadah berbeda didapatkan rangkuman hasil yang ditunjukkan pada Tabel 1 berikut.

Tabel 1. Tingkah Laku Ikan Pada Sampel A, B, dan C.

\begin{tabular}{|c|c|c|c|c|c|c|c|c|c|c|}
\hline \multirow{3}{*}{$\begin{array}{l}\text { Menit } \\
\text { ke }\end{array}$} & \multicolumn{10}{|c|}{ Tingkah Laku (TL) Ikan Cupang Jantan Betina dalam Wadah Berbeda } \\
\hline & \multicolumn{2}{|c|}{ TL 1} & \multicolumn{2}{|c|}{ TL 2} & \multicolumn{2}{|c|}{ TL 3} & \multicolumn{2}{|c|}{ TL 4} & \multicolumn{2}{|c|}{ TL 5} \\
\hline & $(0)$ & १ & $\left(0^{2}\right.$ & () & (0) & () & (O) & (1) & $(0)$ & (1) \\
\hline $1-5$ & & $\mathrm{C}$ & A & & A & & B & $\mathrm{B}$ & A & \\
\hline $6-10$ & & A & B & & B & $\mathrm{A}, \mathrm{C}$ & & & & \\
\hline $11-15$ & & & $\mathrm{C}$ & A & & B & & & $\mathrm{A}, \mathrm{B}$ & \\
\hline $16-20$ & B & A & & & $\mathrm{C}$ & & & & $\mathrm{C}$ & A \\
\hline $21-25$ & & $\mathrm{~B}, \mathrm{C}$ & & & $\mathrm{A}, \mathrm{B}$ & & & & $\mathrm{A}, \mathrm{B}$ & \\
\hline $26-30$ & & & $\mathrm{~A}, \mathrm{~B}, \mathrm{C}$ & & $\mathrm{C}$ & A & & & $\mathrm{B}$ & \\
\hline $31-35$ & A & B & & & & & A & A & $\mathrm{C}$ & B \\
\hline $36-40$ & & $\mathrm{C}$ & & B & & B & & & & \\
\hline $41-45$ & B & A & & C & & A & & & $\mathrm{C}$ & \\
\hline $46-50$ & & $\mathrm{C}$ & B & & $\mathrm{C}$ & & & & & $\mathrm{C}$ \\
\hline $51-55$ & A & & $\mathrm{C}$ & & B & & & & & \\
\hline $56-60$ & $\mathrm{C}$ & B & A & & & B & B & B & $\mathrm{C}$ & \\
\hline Jumlah & 5 & 10 & 9 & 3 & 8 & 7 & 3 & 3 & 10 & 3 \\
\hline
\end{tabular}

Keterangan TL : 1.Diam di Dasar, 2.Berenang Memutari Aquarium, 3.Berenang ke Permukaan. 4.Saling Tatap, 5.Laku Membuat Gelembung.

Berdasarkan Tabel 1 didapatkan hasil tingkah laku ikan cupang jantan pada sampel A, sampel B dan sampel C yang dominan adalah membuat gelembung yaitu sebanyak 10 kali, selanjutnya berenang memutari aquarium sebanyak 9 kali, berenang ke permukaan sebanyak 8 kali, diam di dasar sebanyak 5 kali dan terakhir saling tatap sebanyak 3 kali. Ikan cupang jantan memiliki pola perilaku yang lebih aktif dibandingkan dengan ikan cupang betina, hal tersebut terlihat dari jumlah tingkah laku yang dilakukan oleh ikan cupang jantan selama dalam waktu pengamatan, perilaku dominan ikan cupang jantan yang sering membuat gelembung 
mengakibatkan ditemukannya sarang busa (bubblenest) pada permukaan air wadah ikan cupang jantan. Sarang busa (bubbblenest) yang ditemukan pada permukaan air wadah ikan cupang jantan menandakan bahwa ikan cupang jantan telah siap untuk melakukan pemijahan dan siap untuk menjaga telur-telurnya (Linke, 1994; Sanford,1995).

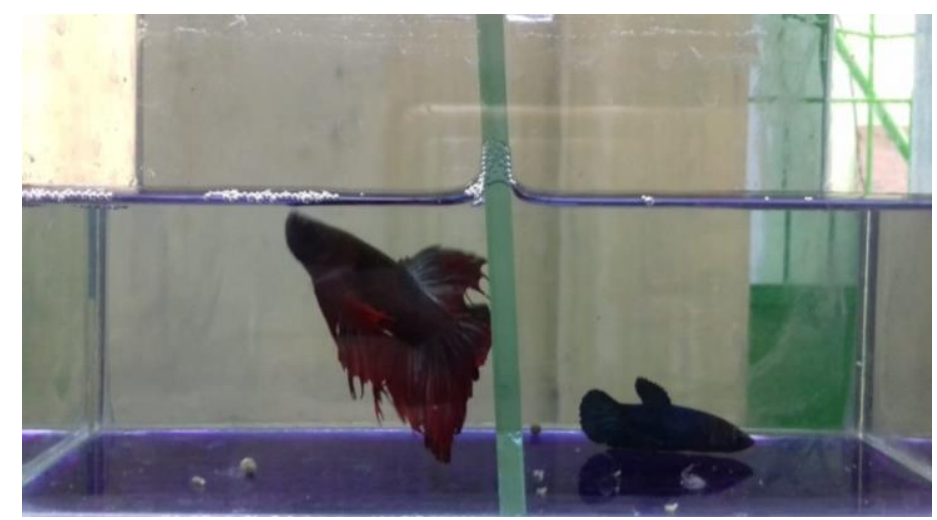

Gambar 3. Ikan Cupang Jantan Membuat Gelembung di Permukaan Air

Sedangkan perilaku ikan cupang betina yang paling dominan adalah diam di dasar aquarium yaitu sebanyak 10 kali, selanjutnya berenang ke permukaan sebanyak 7 kali, berenang memutari aquarium 3 kali, saling tatap 3 kali dan membuat gelembung sebanyak 3 kali. Ikan cupang cupang betina yang cenderung pasif dalam pergerakan, hal tersebut dibuktikan dengan tingkah laku ikan cupang betina yang dominan adalah diam didasar aquarium. Tingkah laku ikan cupang yang cenderung diam dan jarang melakukan pergerakan dapat diakibatkan karena lawan ikan cupang yang ada di hadapan ikan cupang tersebut memiliki ukuran tubuh yang lebih besar.

Interaksi Tingkah Laku Ikan Cupang Dalam Satu Wadah. Setelah dilakukan pengamatan selama 3 hari dalam wadah yang berbeda, selanjutnya ikan cupang jantan dan betina pada masing-masing sampel dimasukkan dalam satu wadah kemudian diamati selama 2 jam. Hasil pengamatan selama 2 jam dapat dilihat pada Tabel 2 dan Gambar 4 berikut.

Tabel 2 . Pola Perilaku Ikan Cupang Jantan dan Betina dalam Satu Wadah

\begin{tabular}{|c|c|c|c|c|c|c|c|c|c|c|c|c|c|}
\hline \multirow{3}{*}{$\begin{array}{c}\text { Menit } \\
\text { ke }\end{array}$} & \multicolumn{13}{|c|}{ Tingkah Laku (TL) Ikan Cupang Jantan Betina dalam Satu Wadah } \\
\hline & \multicolumn{2}{|c|}{ TL 1} & \multicolumn{2}{|c|}{ TL 2} & \multicolumn{2}{|c|}{ TL 3} & TL 4 & \multicolumn{2}{|c|}{ TL 5} & \multicolumn{2}{|c|}{ TL 6} & \multicolumn{2}{|c|}{ TL 7} \\
\hline & $(0)$ & ९ & $(0)$ & 实 & $\left(0^{2}\right.$ & () & (O) & $(0)$ & ? & (O) & (ి) & $(0)$ & O \\
\hline $1-10$ & A & & & $\mathrm{A}, \mathrm{B}$ & $\mathrm{B}, \mathrm{C}$ & & & & & B & & & \\
\hline $11-20$ & B & A & & $\mathrm{B}, \mathrm{C}$ & A & A,B & & & & A & $\mathrm{B}, \mathrm{C}$ & & \\
\hline $21-30$ & $\mathrm{~A}, \mathrm{C}$ & & & $\mathrm{B}$ & B & $\mathrm{C}$ & A & A & & & & & \\
\hline $31-40$ & $\mathrm{C}$ & & $\mathrm{A}, \mathrm{B}$ & A & & & $\mathrm{C}$ & $\mathrm{C}$ & & & B & $\mathrm{C}$ & \\
\hline $41-50$ & & & & $\mathrm{C}$ & $\mathrm{A}, \mathrm{C}$ & $\mathrm{A}, \mathrm{B}$ & & & A & $\mathrm{C}$ & A & & \\
\hline $51-60$ & & & & A & $\mathrm{A}, \mathrm{B}, \mathrm{C}$ & & $\mathrm{B}, \mathrm{C}$ & $\mathrm{B}, \mathrm{C}$ & & & & & \\
\hline $61-70$ & B & B & & & & $\mathrm{C}$ & A & A & & & $\mathrm{C}$ & & \\
\hline $71-80$ & A & & & B & $\mathrm{B}, \mathrm{C}$ & & & & & $\mathrm{B}, \mathrm{C}$ & & B & A \\
\hline $81-90$ & $\mathrm{~B}, \mathrm{C}$ & $\mathrm{C}$ & & A & & B & & & & & B & & \\
\hline $91-100$ & & & A & B & $\mathrm{C}$ & & & & & A & & & \\
\hline $101-110$ & & & $\mathrm{C}$ & & A & & B & B & & & & & \\
\hline $111-120$ & & & & $\mathrm{~B}, \mathrm{C}$ & A & A & & & & & A & & \\
\hline Jumlah & 9 & 3 & 4 & 13 & 14 & 7 & 6 & 6 & 1 & 6 & 7 & 2 & 1 \\
\hline
\end{tabular}

Keterangan : TL 1. Memegarkan Sirip, TL 2. Diam di Dasar Aquarium, TL 3. Berenang Memutari Aquarium, TL 4. Berlari/ Menghindar, TL 5. Mendekati Lawan Jenis, TL 6. Mengambil Oksigen, TL 7. Memiringkan Badan. 


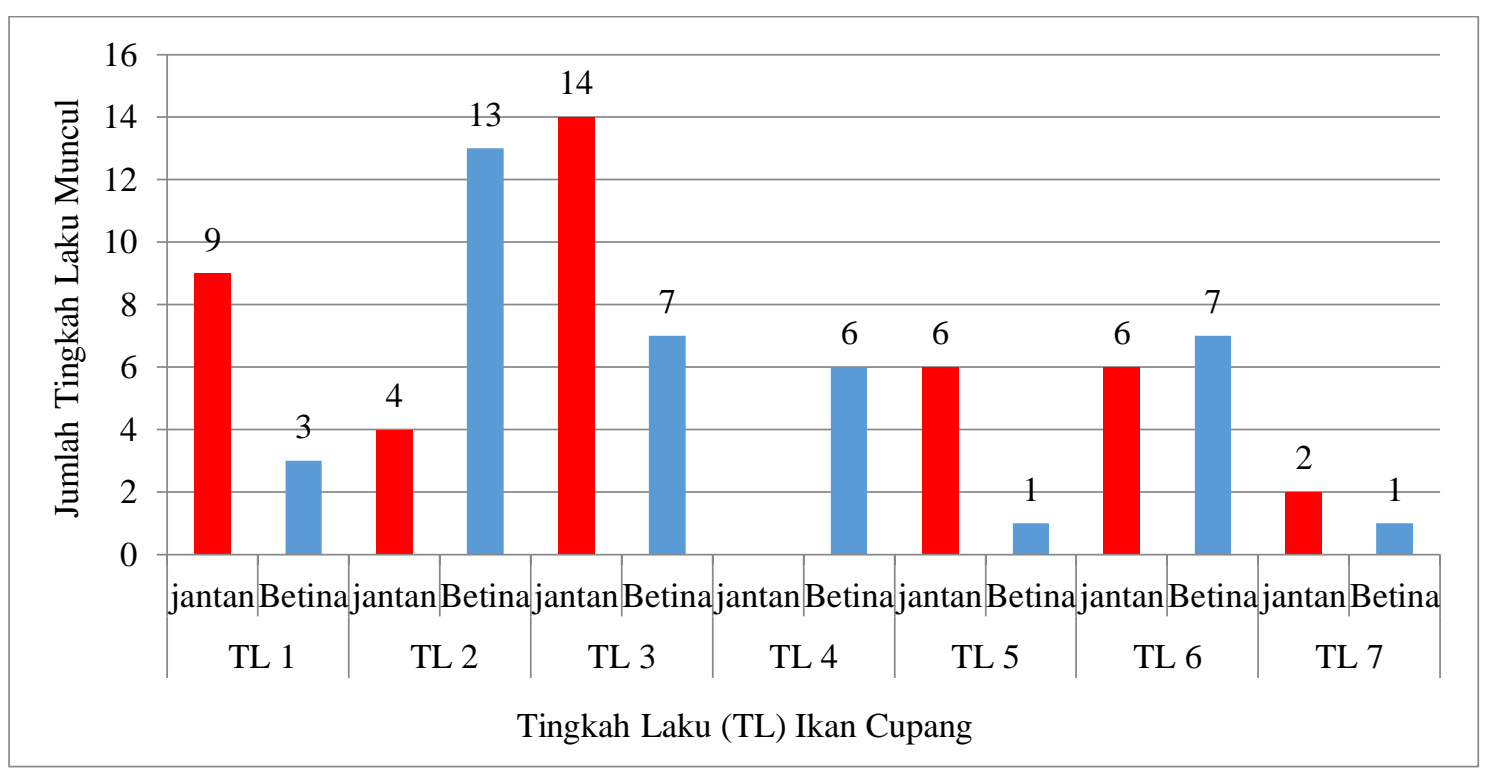

Gambar 4. Tingkah Laku Ikan Cupang Jantang dan Betina dalam Satu Wadah

Keterangan : TL 1. Memegarkan Sirip, TL 2. Diam di Dasar Aquarium, TL 3. Berenang Memutari Aquarium, TL 4. Berlari/ Menghindar, TL 5. Mendekati Lawan Jenis, TL 6. Mengambil Oksigen, TL 7. Memiringkan Badan.

Berdasarkan Gambar 4 dapat diketahui bahwa ikan cupang jantan memiliki perilaku yang dominan yaitu berenang memutari aquarium yaitu sebanyak 14 kali, selanjutnya memegarkan sirip sebanyak 9 kali, mendekati lawan jenis dan mengambil oksigen sebanyak 6 kali, diam di dasar aquarium 4 kali dan memiringkan badan sebanyak 2 kali. Ikan cupang jantan maupun betina menunjukkan tingkah laku yang tidak berbeda jauh dibandingkan dengan saat ikan cupang jantan ditempatkan pada wadah yang berbeda. Ikan cupang jantan cenderung lebih aktif berenang memutari aquarium, ikan cupang jantan juga lebih agresif daripada ikan cupang betina, terbukti dengan perilaku ikan cupang jantan cenderung mendekati betina namun respon dari ikan cupang betina lebih sering berlari menghindari pendekatan yang dilakukan oleh jantan.

Sedangkan ikan cupang betina memiliki perilaku dominan berupa diam di dasar aquarium sebanyak 13 kali, selanjutnya memutari aquarium sebanyak 8 kali, mengambil oksigen sebanyak 7 kali, berlari/ menghindari sebanyak 6 kali, memegarkan sirip sebanyak 3 kali, mendekati lawan jenis 1 kali dan memiringkan badan sebanyak 1 kali. Ikan cupang betina lebih sering berdiam diri di dasar aquarium, dan lebih aktif untuk berenang ke permukaan untuk mengambil oksigen. Pada wadah ikan cupang betina juga tidak ditemukan sarang busa. dengan memegarkan sirip serta mendekati sang betina.

Sesekali terlihat tingkah laku ikan cupang jantan memiringkan tubuh saat mendekati sang betina, namun saat didekati oleh cupang jantan ikan cupang betina justru menghindari atau berlari menjauh dari cupang jantan sehingga terlihat seperti melakukan kejar-kejaran (Gema, 2017). Ikan cupang jantan juga sesekali menabrakkan diri dan bahkan seperti mematuk betina yang menyebabkan sang betina sering berlari jika didekati oleh ikan cupang jantan. Tingkah laku yang dilakukan oleh cupang jantan merupakan aktivitas untuk menarik cupang betina untuk melakukan pemijahan. Lingga \& Susanto (2003) menjelaskan bahwa ikan cupang dapat melakukan pemijahan dalam wadah seperti akuarium dalam ukurang tidak terlalu luas. Pada Gambar 4 dapat dilihat bahwa ikan cupang jantan tidak melakukan perkawinan meskipun pejantan telah membuat sarang busa dan juga umur ikan cupang sudah memenuhi syarat pemijaham (kurang lebih 5 bulan) (Lesmana \& Dermawan, 2001). 
Ada beberapa kemungkinan ikan cupang tidak terjadi penmijahan antara lain suhu air yang berubah saat siang dan malam, $\mathrm{pH}$ air yang tidak optimal dan kondisi psikologis ikan. Dewantoro (2001); Doutrelant et al., (2001); Lingga \& Susanto (2003) menjelaskan bahwa ikan cupang dapat memijah pada malam hari, dengan kondisi lingkungan pada suhu $26,5^{\circ}$ $31,0^{\circ} \mathrm{C}$, DO 6,6-7,3 ppm, pH 6,0-8,0.

\section{KESIMPULAN}

Ikan cupang jantan memiliki pola perilaku yang lebih aktif dan agresif dibandingkan dengan ikan cupang betina, hal tersebut terlihat dari perilaku ikan cupang jantan saat berada di dalam wadah berbeda maupun disatukan dalam satu wadah. Pada wadah yang berbeda, tingkah laku cupang jantan yang paling dominan yaitu membuat gelembung, sedangkan betina lebih sering diam di dasar. Setelah ikan jantan dan betina ditempatkan pada wadah yang sama, maka terlihat tingkah laku ikan cupang jantang yang paling dominan adalah berenang memutari akuarium, sedangkan betina lebih sering diam di dasar akuarium. Meskipun ikan cupang jantan telah membuat sarang busa (bubblenest) yang menandakan ikan cupang siap untuk melakukan reproduksi hal tersebut tidak berarti ikan cupang tersebut pasti akan melakukan pemijahan

\section{SARAN}

Disarankan dalam penelitian selanjutnya untuk memperhatikan pakan dan ukuran tubuh setiap ikan cupang yang akan dilakukan percobaan, agar pengamatanya memperoleh hasil yang maksimal.

\section{DAFTAR PUSTAKA}

Altman, J., (1974), Observation Study Of Behavior Sampling Methods. Behavior Academic Press, London.

Atmajaja, J. (2008). Panduan Lengkap memelihara Ikan Cupang Ikan Cupang Hias dan Cupang Adu. Penebar Swadaya. Jakarta.

Axelrod, H.R. (1995). Encyclopedia of Tropical Fishes: With Special Emphasis on Techniques of Breeding. T.F.H. Publications, Inc. University of California. $631 \mathrm{~h}$.

Axelrod, H. R., \& Schultz, L. P. (1983). Handbook of tropical aquarium fishes. TFH publications.

Dewantoro, G. W. (2017). FEKUNDITAS DAN PRODUKSI LARVA PADAIKAN CUPANG (Betta splendens Regan) YANG BERBEDA UMUR DAN PAKAN ALAMINYA [The Fecundity and Juveniles Products of Fighting Fish (Betta splendens Regan) With Different Age and Natural Food]. Jurnal Iktiologi Indonesia, 1(2), 49-52.

Doutrelant, C., McGregor, P. K., \& Oliveira, R. F. (2001). The effect of an audience on intrasexual communication in male Siamese fighting fish, Betta splendens. Behavioral Ecology, 12(3), 283-286.

Kottelat, M. (2013). The fishes of the inland waters of Southeast Asia: a catalogue and core bibliography of the fishes known to occur in freshwaters, mangroves and estuaries. Raffles Bulletin of Zoology.

Lee, C.K. (1986). Goldfish and Tropical Fish. Tropical Press. SDN. BHD. Kualalumpur.

Lesmana, D. S., \& Dermawan, I. (2001). Budi Daya Ikan Hias Air Tawar Populer. Penerbit Swadaya.

Lingga, P. dan Susanto, H. (2003). Ikan Hias Air Tawar. Penebar Swadaya. Jakarta. h. 45.

Linke, H . (1994). Eksplorasi Ikan Cupang di Kalimantan. Trubus. No.297. Agustus. h. 86-89

Sandford, G. (1995). An illustrated encyclopedia of aquarium fish. Howell Books. 
Satyani, D. (2017). PENGARUH UMUR INDUK IKAN cUPANG (Betta sprenden Regan) DAN JENIS PAKAN TERHADAP FEKUNDITAS DAN PRODUKSI LARVANYA. Jurnal Penelitian Perikanan Indonesia, 9(4), 13-18.

Sterba, G. (1983). The aquarium encyclopedia. Mit Press.

Susanto,H. 1992. Memelihara Cupang. Penerbit Kanisius. Yogyakarta.

Yustina, A. Darmawati. 2003. Daya tetas dan laju pertumbuhan larva ikan hias Betta splendens di habitat buatan. Jurnal Natur Indonesia, 5(2), 129-132.

Yusuf, A., Koniyo, Y., \& Muharam, A. (2015). Pengaruh Perbedaan Tingkat Pemberian Pakan Jentik Nyamuk terhadap Pertumbuhan Benih Ikan Cupang. Jurnal Nike, 3(3). 